\title{
CH-Stretching Vibrational Trends in Natural Gas Hydrates Studied by Quantum-Chemical Computations
}

\author{
Yuan Liu and Lars Ojamäe
}

Linköping University Post Print

Tweet

N.B.: When citing this work, cite the original article.

Original Publication:

Yuan Liu and Lars Ojamäe, CH-Stretching Vibrational Trends in Natural Gas Hydrates Studied by Quantum-Chemical Computations, 2015, The Journal of Physical Chemistry C, (119), 30, 17084-17091.

http://dx.doi.org/10.1021/acs.jpcc.5b01903

Copyright: American Chemical Society

http://pubs.acs.org/

Postprint available at: Linköping University Electronic Press

http://urn.kb.se/resolve?urn=urn:nbn:se:liu:diva-120872 


\title{
CH Stretching Vibrational Trends in Natural Gas Hydrates Studied by Quantum-chemical Computations
}

\author{
Yuan Liu and Lars Ojamäe ${ }^{\dagger}$ \\ Department of Chemistry, IFM, Linköping University, SE-58 183 Linköping, Sweden \\ † Corresponding author. Phone: +46 13281380 Email address: lars@ifm.liu.se
}




\begin{abstract}
:
Vibrational Raman spectroscopy of hydrocarbon $\mathrm{CH}$ stretching vibrations is often used to study natural gas hydrates. In this work, $\mathrm{CH}$ stretching vibrational Raman spectra of hydrocarbon molecules $\left(\mathrm{CH}_{4}, \mathrm{C}_{2} \mathrm{H}_{6}, \mathrm{C}_{3} \mathrm{H}_{6}, \mathrm{C}_{3} \mathrm{H}_{8}, \mathrm{C}_{4} \mathrm{H}_{8}, \mathrm{i}-\mathrm{C}_{4} \mathrm{H}_{10}\right.$, and $\left.\mathrm{n}-\mathrm{C}_{4} \mathrm{H}_{10}\right)$ encapsulated in the water cages (D, ID, T, P, H, and I) of the sI, sII, sH, and sK crystal phases are derived from quantum-chemical computations at the $\omega \mathrm{B} 97 \mathrm{X}-\mathrm{D} / 6-311++\mathrm{G}(2 \mathrm{~d}, 2 \mathrm{p})$ level of theory. The trends of $\mathrm{CH}$ stretching vibrational frequencies of hydrocarbon molecules in NGHs are found to follow the prediction by the "loose cage - tight cage" model: as the size of water cavity increases, the $\mathrm{CH}$ frequencies will first decrease and then increase until equal to that in gas phase. In the "tight cage" situation, the frequency will be greater than in the gas phase; in the "loose cage" situation, the frequency will be smaller or asymptotic to that in the gas phase. Furthermore, the $\mathrm{OH}$ stretching frequencies are sensitive to the H-bond configuration, and the varying strengths of H-bonds for different configurations are reflected by the frequency distribution in the corresponding sub-spectra.
\end{abstract}

Keywords: quantum-chemical computations; natural gas hydrate; Raman spectra; $\mathrm{CH}$ stretching vibration; H-bonding 


\section{INTRODUCTION}

Natural gas hydrate (NGH) are clathrate structures, formed from hydrocarbon gas molecules encapsulated in various water cavities of a H-bonded host lattice. ${ }^{1}$ Many crystal phases can be formed at appropriate temperature and pressure conditions, ${ }^{1}$ e.g. sI, $,{ }^{2} \mathrm{sII},{ }^{3} \mathrm{sH},{ }^{4} \mathrm{sK},{ }^{5} \mathrm{MH}-\mathrm{III},{ }^{6-7}$ and "filled ice". ${ }^{7-8}$ Different kinds of polyhedral cages are included in these phases, shown in Figure 1a-f, namely dodecahedral (D) cages $\left(5^{12}\right)$, irregular dodecahedral (ID) cages $\left(4^{3} 5^{6} 6^{3}\right)$, tetrakaidecahedral $(\mathrm{T})$ cages $\left(5^{12} 6^{2}\right)$, pentakaidecahedral $(\mathrm{P})$ cages $\left(5^{12} 6^{3}\right)$, hexakaidecahedral $(\mathrm{H})$ cages $\left(5^{12} 6^{4}\right)$, and icosahedral (I) cages $\left(5^{12} 6^{8}\right) \cdot{ }^{1,9-10}$

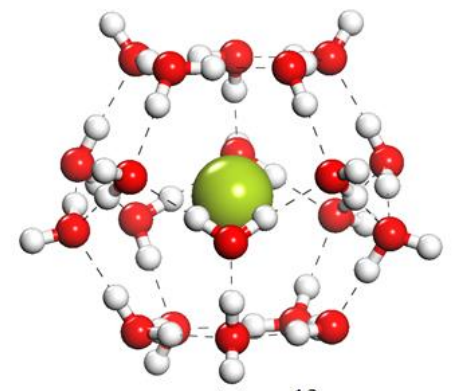

(a) $5^{12}$

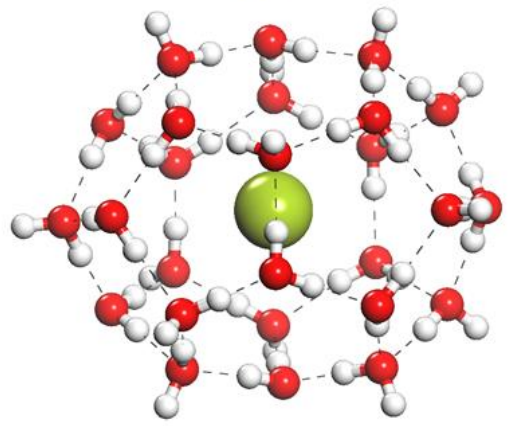

(d) $5^{12} 6^{3}$

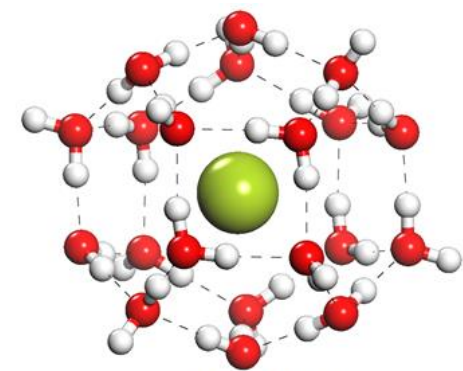

(b) $4^{3} 5^{6} 6^{3}$

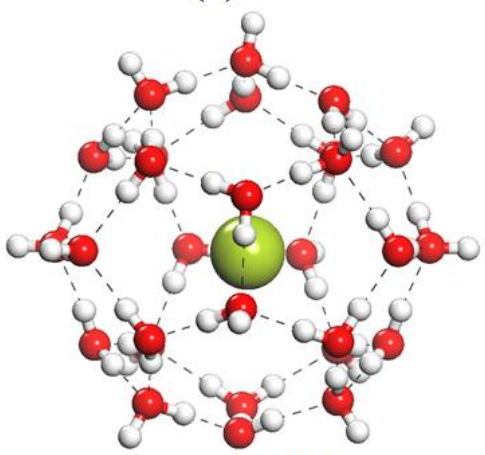

(e) $5^{12} 6^{4}$

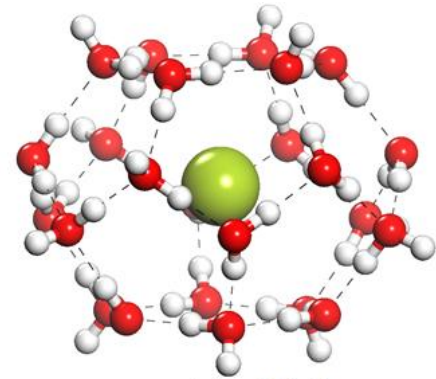

(c) $5^{12} 6^{2}$

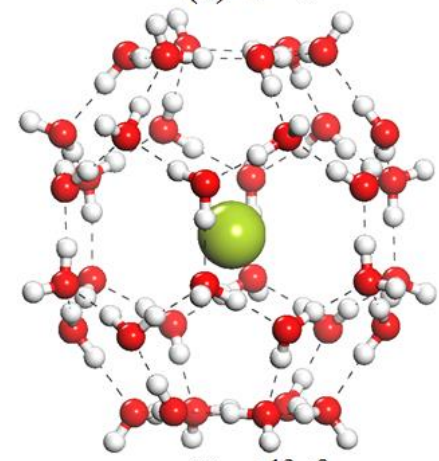

(f) $5^{12} 6^{8}$

Figure 1. Structures of hydrocarbon molecules $\left(\mathrm{CH}_{4}, \mathrm{C}_{2} \mathrm{H}_{6}, \mathrm{C}_{3} \mathrm{H}_{6}, \mathrm{C}_{3} \mathrm{H}_{8}, \mathrm{C}_{4} \mathrm{H}_{8}, \mathrm{i}-\mathrm{C}_{4} \mathrm{H}_{10}\right.$, and n$\mathrm{C}_{4} \mathrm{H}_{10}$ ) encapsulated in various water cages: (a) D cage, (b) ID cage, (c) T cage, (d) P cage, (e) H cage, (f) I cage, from different crystal phases of clathrate hydrates. Colour scheme: red spheres represent oxygen atoms, white spheres represent hydrogen atoms, green spheres represent various hydrocarbon molecules, and black lines represent hydrogen bonds. 
Since NGHs play an important role in energy and environmental fields, for example as a potential backup energy source, as a cause of blockage of oil and gas pipelines, and as a possible initiator of geological disasters and global warming caused by the dissociation of NGHs, a lot of studies have been carried out for NGHs by both experimental ${ }^{9-21}$ and theoretical techniques ${ }^{22-48}$. Experimentally, $\mathrm{CH}$ stretching Raman spectra of guest molecules is often measured as a way to identify the types of crystal phase formed and guest molecules trapped, since the $\mathrm{CH}$ stretching vibrations of hydrocarbon molecules are sensitive to the specific chemical environment. ${ }^{13-15}$ Many applications on NGHs using Raman measurements have been carried out: monitoring of the formation process of methane hydrate in real-time; ${ }^{16}$ observation of the structural transition of mixed gas hydrates; ${ }^{17-18}$ identifying the contents and crystal phases of natural NGH samples exploited from the deposits. ${ }^{19-21}$ Theoretically, the nucleation and growth process of methane hydrate have been simulated and explored on the atomic and molecular level through molecular dynamics simulations. ${ }^{23-30}$ The interaction between host water cages and guest molecules, ${ }^{32,} 41$ stability, diffusion and vibrations of guest molecules in water cavities of clathrate hydrates, ${ }^{31,34,}$ 38-40, 42-43 and phase transition between ice and methane clathrates have been studied by firstprinciple calculations. ${ }^{37,44}$

Experimentally, Raman spectra of hydrocarbon hydrates have demonstrated that the $\mathrm{CH}$ stretching frequency of the guest molecule is commonly (but not always) lower when in a large cage than when in a small cage ${ }^{13-15}$. This observation for hydrates was rationalized by Subramanian and Sloan ${ }^{13}$ in terms of the guest-cage intermolecular interactions using the "loose cage-tight cage" model by Pimentel and Charles designed for rationalization of matrix-isolation IR experiments ${ }^{49}$. Computationally, Tse $^{47}$ performed $a b$ initio $\mathrm{MD}$ simulations for a methane hydrate and obtained a qualitative agreement with experiment. Jiang et al. computed vibrational 
spectra of methane hydrate using classical force-field MD simulations and they also found the stretching frequencies of $\mathrm{CH}_{4}$ to be lower in the larger cavities ${ }^{48}$. Similar results were obtained by Hiratsuka et al. ${ }^{45-46}$ who studied the $\mathrm{CH}$ stretching spectra of $\mathrm{CH}_{4}$ in the structure $\mathrm{I}$ and $\mathrm{H}$ hydrates by ab initio MD simulations.

$\mathrm{Tse}^{47}$ termed the observed downshift for the larger cages "anomalous" with the argument that guest-host interaction should be weaker in a large cage due to the larger free volume, whereas Subramanian and Sloan ${ }^{13}$ used the term rather for the cases where an upshift for a larger cage relative a smaller cage are observed.

The anomalous stretching frequency shift of guest molecules in clathrate hydrates relative to the gas phase is one of the challenging fundamental scientific problems associated with clathrate hydrates $^{47}$. The trends in $\mathrm{CH}$ stretching vibration frequency of hydrocarbon molecules enclosed in clathrate hydrate cages have not yet been completely explained. Moreover, due to the complexity of natural NGH samples, where many types of guest molecules and crystal phases may be present, a multitude of peaks will occur in their Raman spectra. To sort out the peaks contributed from a certain molecule and a particular crystal phase, the information on Raman spectra of potential guest molecules included in NGHs is valuable. To the best of our knowledge, $\mathrm{CH}$ stretching Raman spectra of only a few kinds of organic guest molecules have been obtained from experimental measurements or theoretical computations. ${ }^{1,13,22}$ The Raman spectroscopic data of many guest molecules in $\mathrm{NGH}$ is still lacking. In this paper the $\mathrm{CH}$ Raman stretching vibrations of hydrocarbon gas molecules $\left(\mathrm{CH}_{4}, \mathrm{C}_{2} \mathrm{H}_{6}, \mathrm{C}_{3} \mathrm{H}_{6}, \mathrm{C}_{3} \mathrm{H}_{8}, \mathrm{C}_{4} \mathrm{H}_{8}, \mathrm{i}-\mathrm{C}_{4} \mathrm{H}_{10}\right.$, and n- $\left.\mathrm{C}_{4} \mathrm{H}_{10}\right)$ encapsulated in the water cages (D, ID, T, P, H, and I) from the sI, sII, sH, and sK crystal phases are calculated through quantum-chemical ab initio computations. The variation of the $\mathrm{CH}$ stretching frequency when the guest molecule or clathrate cage is altered is then discussed in relation to the "loose cage - tight cage" model by Pimentel and Charles ${ }^{49}$. The $\mathrm{OH}$ vibrations of 
water molecules in each cage are also analyzed, which is not often the focus in Raman studies on hydrates. ${ }^{21}$ The features of the theoretical hydrocarbon $\mathrm{CH}$ stretching spectra will be of help when identifying the types of guest molecules and crystal phases in the natural NGH samples.

\section{THEORETICAL METHODS}

2.1 Computational Details. The molecular geometries of various water cages (Figure 1) are obtained from the crystalline structures of $\mathrm{sI}^{2}{ }^{2} \mathrm{sII},{ }^{3} \mathrm{sH},{ }^{4}$ and $\mathrm{sK}^{5}{ }^{5}$ To obtain a likely most stable structure and avoid deformation of the empty water cage, we adjusted the arrangement of the hydrogen atoms to minimize the number of the nearest neighbor pairs that both have a dangling $\mathrm{H}$ as has been found in previous work to be the most important H-bond topology factor for determining the cage stability.${ }^{50}$

The guest molecules $\left(\mathrm{CH}_{4}, \mathrm{C}_{2} \mathrm{H}_{6}, \mathrm{C}_{3} \mathrm{H}_{6}, \mathrm{C}_{3} \mathrm{H}_{8}, \mathrm{C}_{4} \mathrm{H}_{8}, \mathrm{i}-\mathrm{C}_{4} \mathrm{H}_{10}\right.$, and n- $\left.\mathrm{C}_{4} \mathrm{H}_{10}\right)$ were initially put at the center of each water cage, which were then allowed to relax to a local-minimum orientation in the water cage through geometry optimization using the $\mathrm{CVFF}^{51}$ force-field method with the water cage frozen. Subsequently, the whole clusters are fully relaxed using the $\omega \mathrm{B} 97 \mathrm{X}-\mathrm{D}^{52}$ functional with the $6-311++\mathrm{G}(2 \mathrm{~d}, 2 \mathrm{p})$ basis set using the Gaussian 09 program. ${ }^{53}$ This dispersionand long range-corrected density functional together with the large, near complete, basis set used here has been found previously in an evaluation of various functionals to accurately (in comparison to MP2 and complete basis set calculations) describe the intermolecular interactions of methane and a water cage. ${ }^{32}$ A molecular cluster model is thus utilized in this work, rather than a periodic model. Whereas a periodic model would be beneficial in order to incorporate longrange effects from the host lattice, the molecular model allowed us to use the present large basis set and functional as well as facilitated the large amount of calculations for the many guest-cage combinations in this study. 
Raman spectra of guest molecules trapped in various water cages were modeled. In this article, the contributions from the hydrogen atoms belonging to hydrocarbon molecules $\left(\mathrm{CH}_{4}, \mathrm{C}_{2} \mathrm{H}_{6}\right.$, $\mathrm{C}_{3} \mathrm{H}_{6}, \mathrm{C}_{3} \mathrm{H}_{8}, \mathrm{C}_{4} \mathrm{H}_{8}, \mathrm{i}-\mathrm{C}_{4} \mathrm{H}_{10}$, and $\left.\mathrm{n}-\mathrm{C}_{4} \mathrm{H}_{10}\right)$ or $\mathrm{H}_{2} \mathrm{O}$ to the $\mathrm{CH}$ and $\mathrm{OH}$ stretching vibrational modes are identified in a similar way as in Refs. 54 and 55. ${ }^{54-55}$ Since each vibrational mode in principle contains contributions from all the atoms in a system, the contribution of each atom to the vibrational mode can be quantified by the ratio of the square of the amplitude of the normalcoordinate of that atom to the sum of amplitudes squared of all atoms. This enables us to project out the contribution to the intensity of a given normal mode from atoms of a specific type:

$$
I_{i}^{\mathrm{X}}=\frac{\sum_{j=\text { atom } \in \mathrm{X}}\left|\vec{C}_{j, i}\right|^{2}}{\sum_{k=1, \text { all atoms }}\left|\vec{C}_{k, i}\right|^{2}} \cdot I_{i}
$$

$I_{i}$ denotes the amplitude of the vibrational mode $i ; X$ represents a group of atoms of a specific type, i.e. the hydrogens that belong to a hydrocarbon molecule or $\mathrm{H}_{2} \mathrm{O}$ groups; $\vec{C}_{j, i}$ is the vector of the $\mathrm{x}, \mathrm{y}, \mathrm{z}$, components of the amplitude of normal-mode $i$ for atom $j ; I_{i}^{\mathrm{X}}$ is the contribution to the Raman intensity of normal mode $i$ from the atoms that belong to group X.

Due to both shortcomings of the level of electronic-structure theory used and the neglect of anharmonicity in the normal-mode computations, the calculated and experimental frequencies will differ, and to compensate for both effects vibrational frequencies obtained from quantumchemical methods are often multiplied by a scaling factor. ${ }^{56}$ The computed $\mathrm{CH}$ and $\mathrm{OH}$ stretching vibrational wavenumbers are therefore scaled using the following formula, which was obtained from linear fitting to the experimental versus computed frequencies (see Table S1) for isolated hydrocarbon gas molecules $\left(\mathrm{CH}_{4}, \mathrm{C}_{2} \mathrm{H}_{6}, \mathrm{C}_{3} \mathrm{H}_{6}, \mathrm{C}_{3} \mathrm{H}_{8}, \mathrm{C}_{4} \mathrm{H}_{8}\right.$, and $\left.\mathrm{n}-\mathrm{C}_{4} \mathrm{H}_{10}\right)$ :

$$
\tilde{v}_{\text {scaled }}=0.94 \times \tilde{v}_{\text {calc }}+50.9
$$


Table S1 lists for the isolated (i.e. gas-phase) hydrocarbon molecules the experimental frequencies included in the fitting and the calculated frequencies. In Table 1 a comparison is made between our computed and the experimental ${ }^{13}$ frequencies for $\mathrm{CH}_{4}$ and for $\mathrm{C}_{2} \mathrm{H}_{6}$ encapsulated in clathrate cages. It is seen that the computed frequencies for $\mathrm{CH}_{4}$ in the clathrate cages after scaling are systematically overestimated by $5-8 \mathrm{~cm}^{-1}$ as compared to the experimental methane hydrate frequencies (and are within that limit also for encapsulated $\mathrm{C}_{2} \mathrm{H}_{6}$ if comparison is made to the mean of the experimental Fermi resonance doublet bands).

Table 1. C-H symmetric stretching vibrational frequencies of $\mathrm{CH}_{4}$ and $\mathrm{C}_{2} \mathrm{H}_{6}$ encapsulated in water cages from clathrate hydrates.

\begin{tabular}{|c|c|c|c|c|c|c|}
\hline $\begin{array}{c}\mathrm{C}-\mathrm{H} \text { stretching } \\
\text { frequencies/cm }\end{array}$ & $\mathrm{CH}_{4} @ \mathrm{D}$ & $\mathrm{CH}_{4} @ \mathrm{ID}$ & $\mathrm{CH}_{4} @ \mathrm{~T}$ & $\mathrm{CH}_{4} @ \mathrm{H}$ & $\mathrm{C}_{2} \mathrm{H}_{6} @ \mathrm{~T}$ & $\mathrm{C}_{2} \mathrm{H}_{6} @ \mathrm{H}$ \\
\hline This work $^{2}$ & 2921 & 2910 & 2913 & 2910 & 2925 & 2921 \\
\hline Expt. $^{a}$ & $2913-2915$ & 2905 & 2905 & 2904 & $2891,2946^{b}$ & $2887,2942^{b}$ \\
\hline
\end{tabular}

${ }^{a}$ References $13-15 .{ }^{b}$ Fermi resonance doublet bands ${ }^{13}$.

The effect from the placement of a guest molecule at different local energy-minimum positions within the cage on the $\mathrm{CH}$ stretching frequency was studied (shown in Figure S1). Both the symmetric and antisymmetric $\mathrm{CH}$ stretching vibrational modes of methane located at several different positions in the $\mathrm{D}, \mathrm{T}$, and $\mathrm{P}$ cages were investigated, and also the $\mathrm{CH}$ stretching vibrations of ethane enclosed in three different positions in the $\mathrm{H}$ cage. The largest difference of the $\mathrm{CH}$ vibrational frequency among different position are $11 \mathrm{~cm}^{-1}, 5 \mathrm{~cm}^{-1}, 11 \mathrm{~cm}^{-1}$, and $3 \mathrm{~cm}^{-1}$ for $\mathrm{CH}_{4} @ \mathrm{D}, \mathrm{CH}_{4} @ \mathrm{~T}, \mathrm{CH}_{4} @ \mathrm{P}$, and $\mathrm{C}_{2} \mathrm{H}_{6} @ \mathrm{H}$, respectively. Just as different positions of guest molecules have a minor effect on cohesive energy (see Figure 3 in Ref. 31), the position is seen to 
have only a small influence on the $\mathrm{CH}$ stretching vibrational frequency.

For the empty water cages, the Raman spectra in the $\mathrm{OH}$ stretching region are split into subspectra for different groups of hydrogen bonds according to their local conformations. Based on the arrangement of $\mathrm{H}$-bonds around the molecule that donate the $\mathrm{H}$-bond, the donor, and around the molecule that accepts the H-bond, the acceptor (Figure S2), the H-bonds are classified into 4 different groups according to the specific donor-acceptor contributions: (a) SD-SA, (b) SD-DA, (c) DD-SA, (d) DD-DA (SD: single donor, SA: single acceptor, DD: double donor, DA: double acceptor), where the first two letters correspond to the molecule donating the H-bond and the following two letters the molecule accepting the H-bond. In addition, there is one group corresponding to the non-H-bonded hydrogens (referred to as "Free H"). From the contribution from the hydrogens (the contribution from the oxygen atoms is close to zero) in respective group, the Raman spectra of $\mathrm{OH}$ stretching vibrational modes of each water cage are split into 5 parts using formula 1 (in this case $\mathrm{X}=\mathrm{SD}-\mathrm{SA}, \mathrm{SD}-\mathrm{DA}, \mathrm{DD}-\mathrm{SA}$, DD-DA, or Free H). ${ }^{54-55}$

2.2 Loose Cage - Tight Cage (LCTC) Model. An expression for the vibrational frequency shift $(\Delta v)$ due to solute-solvent interactions of a dissolved molecule was derived by Buckingham from analysis of the frequency shift of an oscillator when it interacts with an external potential using quantum-mechanical perturbation theory. ${ }^{57}$ This expression was used in the studies by Pimentel and Charles to explain matrix-isolation experiment effects in terms of the sizes of the cages surrounding the dissolved molecules. ${ }^{49}$ We here use the Buckingham formula to describe the frequency shift of molecules encapsulated in water cages, where the host-guest interaction corresponds to the intermolecular or solute-solvent interaction similar to as in Ref. $13 .{ }^{13}$ We note that we can simplify and rewrite the Buckingham formula for the frequency shift due to the environment as: 


$$
\Delta v=v_{\text {cage }}-v_{\text {gas }}=\frac{v_{e}}{2 k}\left[U^{\prime \prime}-\frac{u_{B C}^{\prime \prime \prime}}{k} U^{\prime}\right]
$$

In the present context $v_{\text {cage }}$ and $v_{\text {gas }}$ are the intramolecular vibrational frequencies of the guest molecule trapped in the water cages and in the gas phase; $v_{e}$ is the harmonic vibrational frequency of the guest molecule in gas phase; $U$ is the host-guest interaction potential energy as a function of the intramolecular bond length $r, U^{\prime}$ and $U^{\prime \prime}$ are the first and second derivatives of $U$ with respect to $r$ evaluated at the equilibrium intramolecular bond length $r_{e} ; k$ the harmonic force constant for the particular vibrational mode of the guest molecule; $u_{B C}^{\prime \prime \prime}$ is the third derivative of the intramolecular bond stretching potential energy $u_{B C}$ evaluated at $r_{e}$. It can be noted that the Buckingham formula for the solvent shift is valid using both classical and quantum mechanics ${ }^{58}$. (We performed a test calculation for a methane molecule in a hydrate cage, where the total potential energy function as a function of the $\mathrm{CH}$ bond length for a symmetric stretching mode was computed. From the potential energy function of an isolated $\mathrm{CH}_{4}$ molecule phase the third derivative of the intramolecular potential at the minimum was calculated. The intermolecular potential energy was obtained as the difference between the total and the intramolecular potential energy functions, and for this intermolecular potential the first and second derivatives were calculated. The frequency downshift relative the isolated molecule computed for the total potential was $15 \mathrm{~cm}^{-1}$, whereas the Buckingham formula, using the above mentioned derivatives, resulted in a downshift of $12 \mathrm{~cm}^{-1}$. This is rather close considering that the solvent influence is represented by only the first few orders of perturbation in the Buckingham formula. In this work, however, we use the Buckingham formula just to qualitatively explain the trends observed for the vibrational frequencies.)

Figure 2a depicts a bent triatomic molecules ABC encapsulated in a water cage as in Ref. 49. 
The water molecules $\mathrm{M}$ are considered to be rigidly positioned by the lattice and the movements of the $\mathrm{AB}$ atoms are ignored, where the interaction energy $U_{C M}$ between $\mathrm{C}$ and $\mathrm{M}$ is approximatively a function of $r=r_{B C}$ only.

$R_{\mathrm{e}}, R_{1}$, and $R_{2}$ corresponds to the $R_{\mathrm{CM}}$ distances at the $U_{C M}, U^{\prime}$ and $U^{\prime \prime}$ minima, respectively. If $R_{\mathrm{CM}}<R_{\mathrm{e}}$, both $U^{\prime}$ and $U^{\prime \prime}$ are positive; since $u_{B C}^{\prime \prime \prime}$ is negative, $\Delta v$ will be positive, the stretching frequency of the guest molecule is greater than in the gas phase. This is the "tight cage" scenario. When $R_{\mathrm{CM}}$ decreases (corresponding to the size of the water cage decreasing or the size of the guest molecule increasing), both $U^{\prime}$ and $U^{\prime \prime}$ increase, therefore, $\Delta v$ will increase as the cage becomes smaller or the guest molecule becomes larger. In other words, the vibrational frequency of the guest molecules will increase as the size of cage decreases or the size of the guest molecule increases. On the other hand, if $R_{\mathrm{CM}}>R_{1}$, both $U^{\prime}$ and $U^{\prime \prime}$ are negative, and $\Delta v$ will be negative, so that the stretching frequency of guest molecule will be less than in the gas phase. This is the "loose cage" scenario. If $R_{\mathrm{CM}}>R_{2}$, both $U^{\prime}$ and $U^{\prime \prime}$ are negative but tend towards zero when $R_{\mathrm{CM}}$ increases. Thus $\Delta v$ will increase (the absolute value of $\Delta v$ will decrease due to it being negative) as the cage become larger or guest molecule become smaller, i.e. the vibrational frequency of the guest molecule will increase. However, when $R_{1}<R_{\mathrm{CM}}<R_{2}, U^{\prime \prime}$ decreases and $U^{\prime}$ increases as $R_{\mathrm{CM}}$ increases, which makes it difficult to predict how $\Delta v$ changes except that it should be negative. When $R_{\mathrm{e}}<R_{\mathrm{CM}}<R_{1}$, both $U^{\prime}$ and $U^{\prime \prime}$ will decrease if $R_{\mathrm{CM}}$ increases, and $\Delta v$ will consequently decrease. In this case the vibrational frequency of the guest molecule will decrease as the size of the cage increases or the size of the guest molecule decreases. 


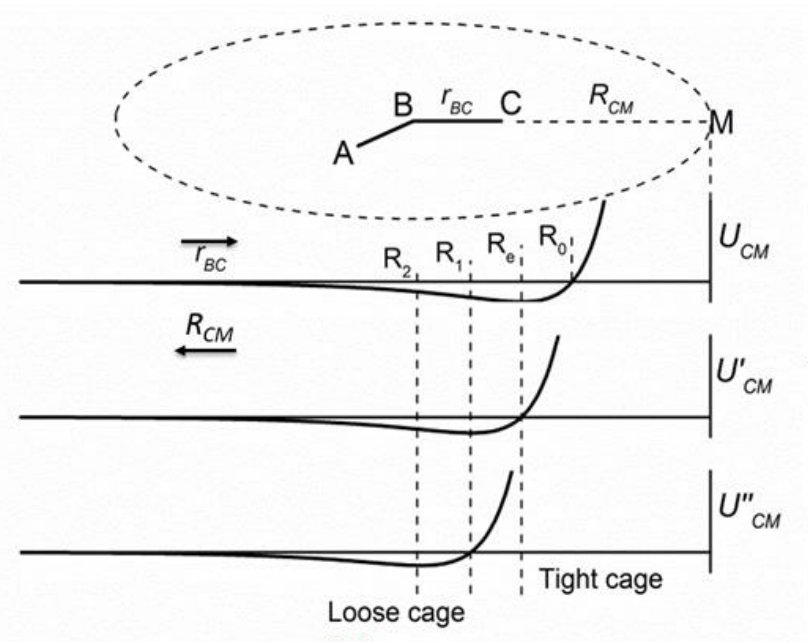

(a)

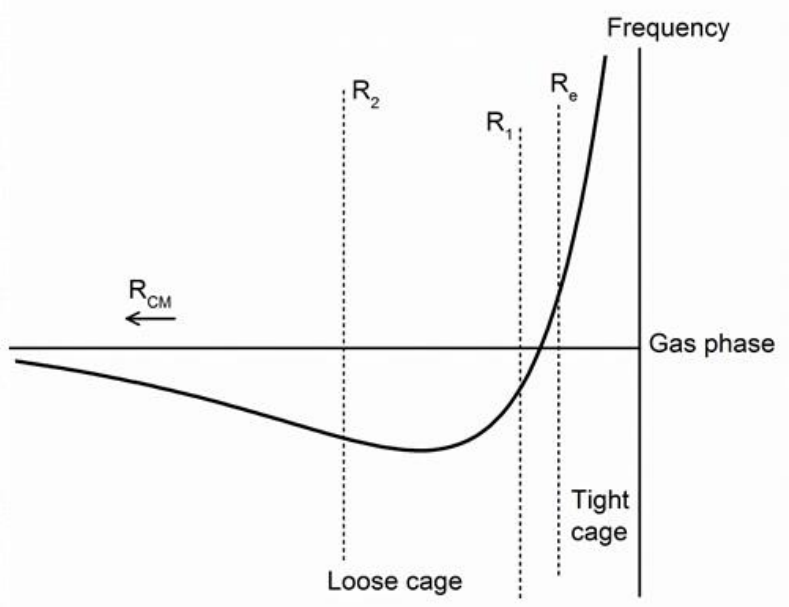

(b)

Figure 2. (a) Dependence of interaction potential functions $U, U^{\prime}$ and $U^{\prime \prime}$ on cage size. (b) The $\mathrm{CH}$ stretching frequency of a guest molecule in clathrate hydrate as a function of the size of the water cavities as deduced from LCTC model.

The general trends for the vibrational frequencies of guest molecules encapsulated in water cages as predicted by the LCTC model can be summarized (see Figure 2b):

a) In the "tight cage" situation $\left(\mathrm{R}_{\mathrm{CM}}<\mathrm{R}_{\mathrm{e}}\right)$, the vibrational frequency will be larger than in gas phase; in the "loose cage" situation $\left(\mathrm{R}_{\mathrm{CM}}>\mathrm{R}_{1}\right)$, the vibrational frequency will be smaller than in gas phase.

b) If $R_{C M}<R_{1}$, the vibrational frequency of the guest molecule will decrease as the size of cage increases or the size of the guest molecule decreases.

c) If $\mathrm{R}_{\mathrm{CM}}>\mathrm{R}_{2}$, the vibrational frequency of the guest molecule will increase as the size of the cage increases or the size of the guest molecule decreases, and vice versa. This case contradicts the rule stated in Ref. 13: "the larger the cavity, the lower the frequency" for stretching vibrations. ${ }^{13}$ 


\section{RESULTS AND DISCUSSION}

3.1 CH Stretching Vibrations. The $\mathrm{CH}$ stretching vibrational frequencies of all the hydrocarbon molecules $\left(\mathrm{CH}_{4}, \mathrm{C}_{2} \mathrm{H}_{6}, \mathrm{C}_{3} \mathrm{H}_{6}, \mathrm{C}_{3} \mathrm{H}_{8}, \mathrm{C}_{4} \mathrm{H}_{8}, \mathrm{i}-\mathrm{C}_{4} \mathrm{H}_{10}\right.$, and $\left.\mathrm{n}_{-} \mathrm{C}_{4} \mathrm{H}_{10}\right)$ encapsulated in the different water cages (D, ID, T, P, H, and I) and in the gas phase are presented in Figure 3 and in Table S2.

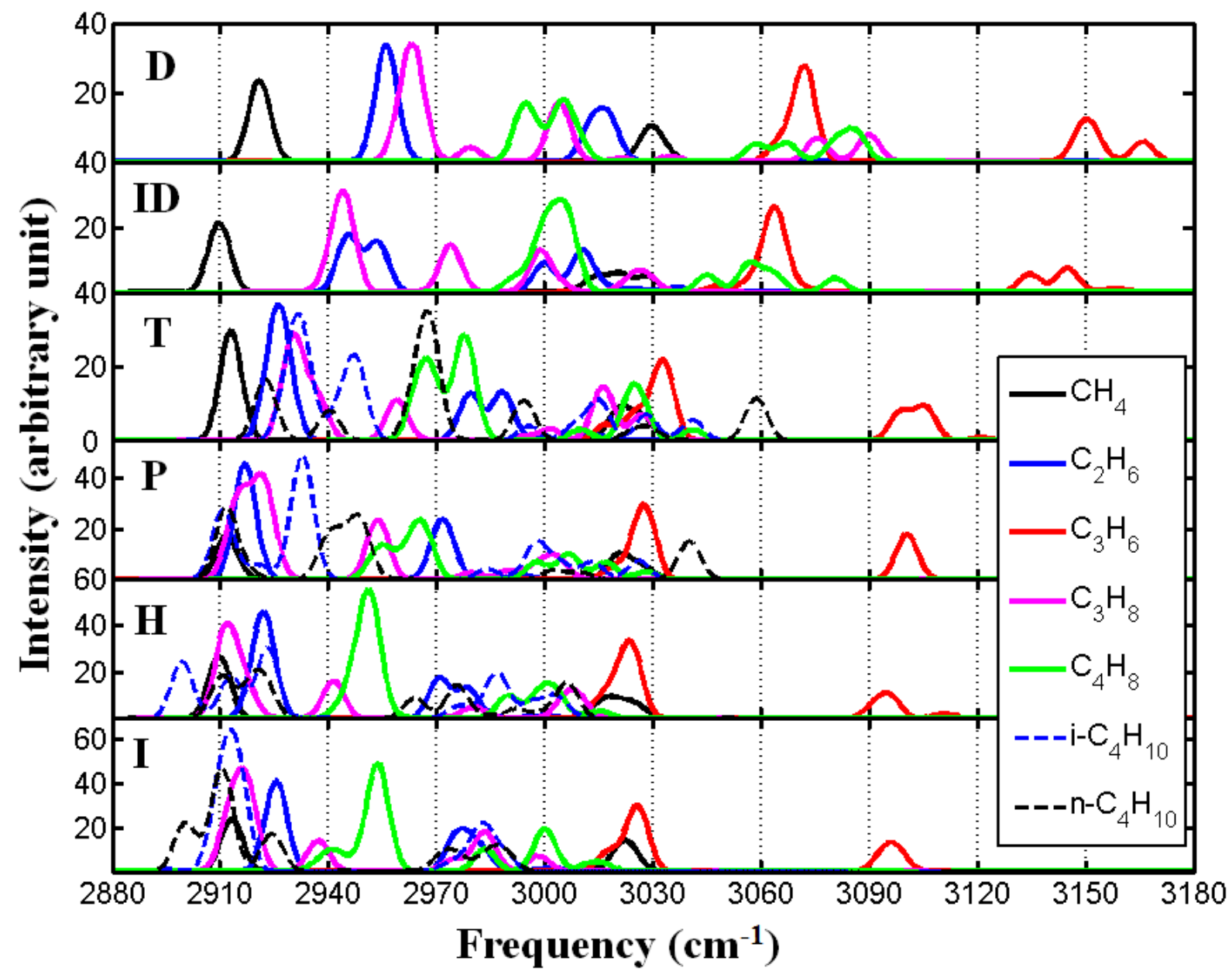

Figure 3. The computed C-H stretching Raman spectra of $\mathrm{CH}_{4}, \mathrm{C}_{2} \mathrm{H}_{6}, \mathrm{C}_{3} \mathrm{H}_{6}, \mathrm{C}_{3} \mathrm{H}_{8}, \mathrm{C}_{4} \mathrm{H}_{8}, \mathrm{i}-\mathrm{C}_{4} \mathrm{H}_{10}$, and $\mathrm{n}-\mathrm{C}_{4} \mathrm{H}_{10}$ in the different water cages. Each peak has been smoothened through multiplication by a Gaussian distribution function with standard deviation $3 \mathrm{~cm}^{-1}$.

For $\mathrm{CH}_{4}$, the symmetric and antisymmetric $\mathrm{CH}$ stretching vibrational frequencies are found to 
decrease when going from the $\mathrm{D}$ cage to the $\mathrm{H}$ cage, then increase from the $\mathrm{H}$ cage to the I cage, and further to the gas phase, which corresponds to the region $\mathrm{R}_{\mathrm{CM}}>\mathrm{R}_{1}$ in the LCTC model (see Figure 4a). Furthermore, the $\mathrm{CH}$ symmetric stretching frequency difference between $\mathrm{CH}_{4}$ in the $\mathrm{D}$ and in the T cage is $8 \mathrm{~cm}^{-1}$, which is quite close to experimentally observed $10 \mathrm{~cm}^{-1}$ (see also Table 1). ${ }^{13}$ The $\mathrm{CH}$ frequency difference between $\mathrm{CH}_{4}$ in the $\mathrm{D}$ and in the $\mathrm{H}$ cage $\left(11 \mathrm{~cm}^{-1}\right)$ coincides with the experimental result $\left(11 \mathrm{~cm}^{-1}\right) \cdot{ }^{13}$ The shift between the D and ID cages of 11 $\mathrm{cm}^{-1}$ also agrees very well with the experimental value $10 \mathrm{~cm}^{-1} \cdot{ }^{13}$ For comparison, for $\mathrm{CH}_{4}$ Hiratsuka et al obtained a symmetric stretching frequency shift of $8 \mathrm{~cm}^{-1}$ between the $\mathrm{D}$ and $\mathrm{T}$ cages ${ }^{45}$ and of $4 \mathrm{~cm}^{-1}$ between the D and ID cages ${ }^{46}$ using AIMD simulations, and Jiang et al. ${ }^{48} \mathrm{a}$ shift of $13 \mathrm{~cm}^{-1}$ between the $\mathrm{D}$ and $\mathrm{T}$ cages from force-field MD simulations.

Regarding $\mathrm{C}_{2} \mathrm{H}_{6}$, both the symmetric and antisymmetric $\mathrm{CH}$ stretching vibrational frequencies are first red-shifted when going from the $\mathrm{D}$ to the $\mathrm{P}$ cage and then blue-shifted going from the $\mathrm{P}$ to the I cage as the size of water cages increase (see Figure 4b), which corresponds to a continuous transition from the "tight cage" to the "loose cage" situation. For $\mathrm{C}_{3} \mathrm{H}_{6}$, the $\mathrm{CH}$ frequency also first decreases and then increases as the size of water cage increases as shown in Figure $4 \mathrm{c}$, following the trend predicted by the LCTC model. For $\mathrm{C}_{3} \mathrm{H}_{8}$, both the symmetric and antisymmetric $\mathrm{CH}$ stretching vibrational frequencies are more and more red-shifted as the size of water cage increases (see Figure $4 d$ ). Regarding $\mathrm{C}_{4} \mathrm{H}_{8}, \mathrm{i}-\mathrm{C}_{4} \mathrm{H}_{10}$, and $\mathrm{n}-\mathrm{C}_{4} \mathrm{H}_{10}$, both the symmetric and antisymmetric $\mathrm{CH}$ stretching frequencies continuously decrease going from the small cage to the large cage, and all of them are greater than in the gas phase (see Figure 4e-g), corresponding to the "tight cage" case in the LCTC model. The host-guest complex exhibits an attractive $\mathrm{H}$ wall interaction in the "loose cage" situation causing the $\mathrm{C}-\mathrm{H}$ bond of the guest molecule to be elongated (see Table S3) and C-H stretching frequency to be red-shifted relative the gas phase. 
The opposite is true in the "tight cage" situation, where the C-H bond is contracted (see Table S3) and the $\mathrm{C}-\mathrm{H}$ stretching frequency is blue-shifted. 
(b)

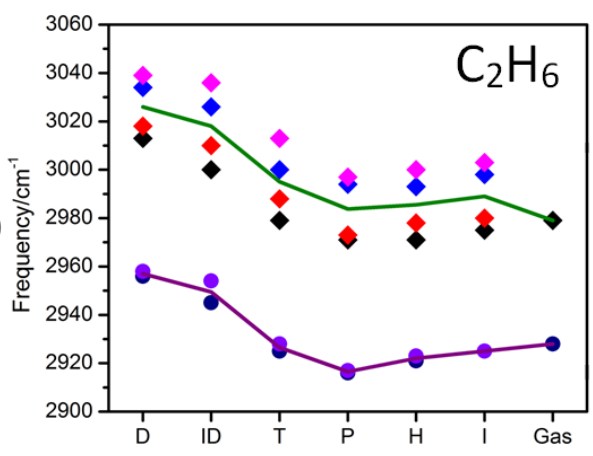

(d)

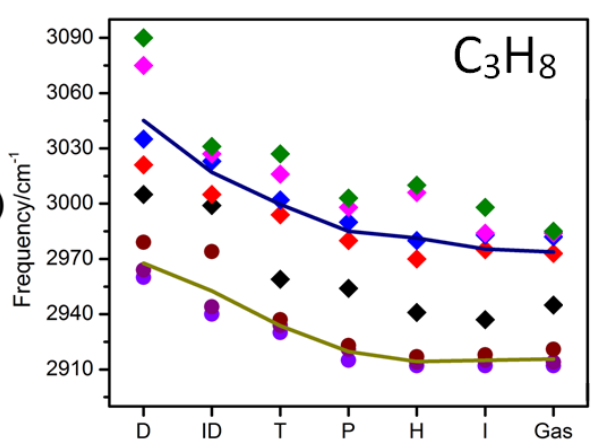

(f)

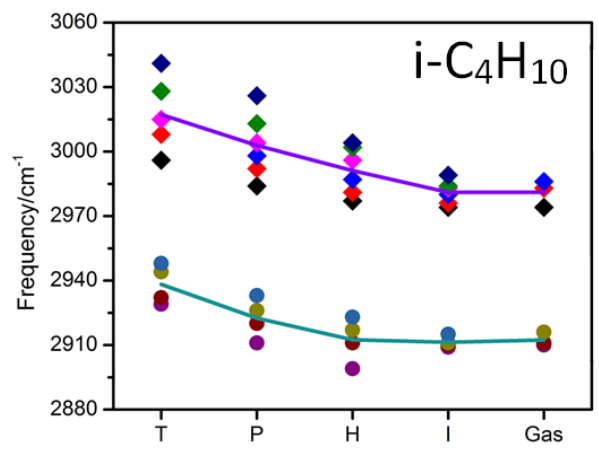

(c)

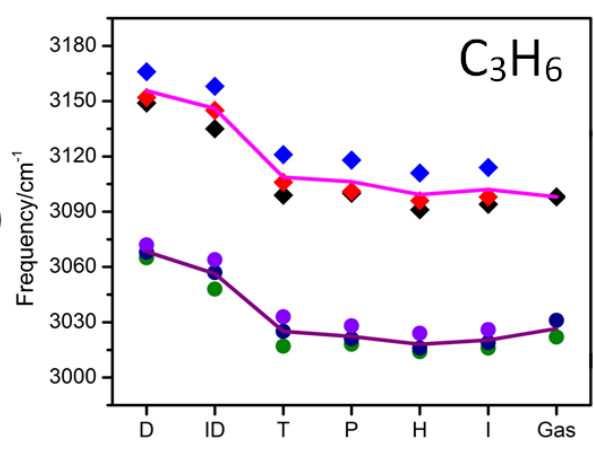

(e)

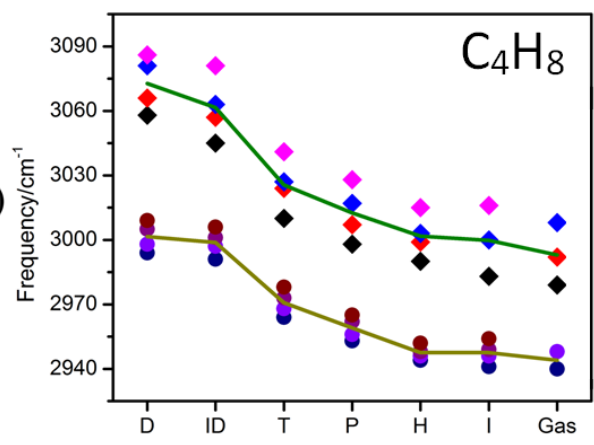

(g)

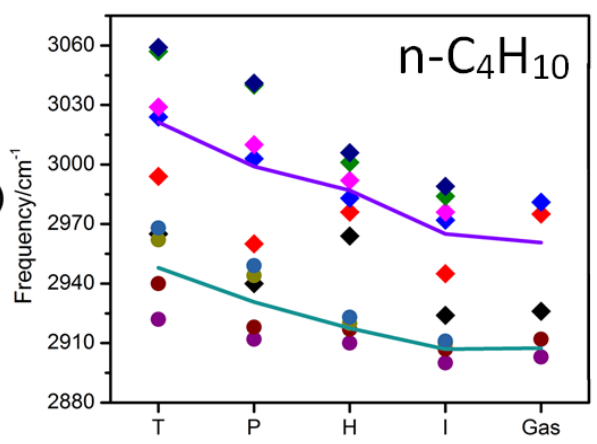

Figure 4. The $\mathrm{C}-\mathrm{H}$ stretching frequencies of (a) $\mathrm{CH}_{4}$, (b) $\mathrm{C}_{2} \mathrm{H}_{6}$, (c) $\mathrm{C}_{3} \mathrm{H}_{6}$, (d) $\mathrm{C}_{3} \mathrm{H}_{8}$, (e) $\mathrm{C}_{4} \mathrm{H}_{8}$, (f) i$\mathrm{C}_{4} \mathrm{H}_{10}$, and $(\mathrm{g}) \mathrm{n}-\mathrm{C}_{4} \mathrm{H}_{10}$ in the different water cages and in the gas phase. The diamonds denote antisymmetric ("A") and the circles symmetric ("S") stretching vibrations. The solid lines represent the mean values of the antisymmetric and symmetric frequencies, respectively. 
3.2 OH Stretching Vibrations. In Figure 5, the Raman spectra for the $\mathrm{OH}$ stretching vibrational modes of various empty water cages in NGHs are divided into sub-spectra based on the specific contributions from groups of hydrogen atom in different $\mathrm{H}$-bond configurations. The $\mathrm{OH}$ stretching frequencies of dangling hydrogens are located at the highest frequency part of the spectra, between 3700 and $3800 \mathrm{~cm}^{-1}$. The $\mathrm{OH}$ stretching vibrations of the SD-SA group are located at the lowest-frequency part, lower than $3200 \mathrm{~cm}^{-1}$. The middle parts are contributions from the DD-DA, DD-SA, and SD-DA groups, where the OH frequencies of the DD-DA group are higher than those of the other two groups, and the peaks from the DD-SA and SD-DA groups overlap. The frequencies of the DD group (DD-DA/SA) are higher than that of the SD group (SD-DA/SA); and the frequencies of the DA group (DD/SD-DA) are higher than that of the SA group (DD/SD-SA). Therefore, the $\mathrm{OH}$ stretching frequency is sensitive to the configuration of the H-bond ${ }^{5-55,59}$. For example in Ref. 55 it was seen for the 20 -molecule water cage that $\mathrm{H}$ bond topologies with similar energies gave similar IR spectra, whereas high-energy topologies gave very different spectra with notably $\mathrm{OH}$ frequencies shifted to higher wavenumbers. As is well known from the Badger-Bauer rule ${ }^{60-62}$ (originally from studies of acids and alcohols in solutions and pure liquids in 1937), the $\mathrm{OH}$ stretching frequency of $\mathrm{H}_{2} \mathrm{O}$ depends on the strength of the H-bond: the greater the strength of the H-bond, the lower the $\mathrm{OH}$ frequency, and vice versa. Thus, the relationship between the strength of H-bonds and their configurations is reflected by the relative positions of the different sub-spectra, which can be of help to identify the specific Hbond situations from measurement of $\mathrm{O}-\mathrm{H}$ vibrational spectra. 


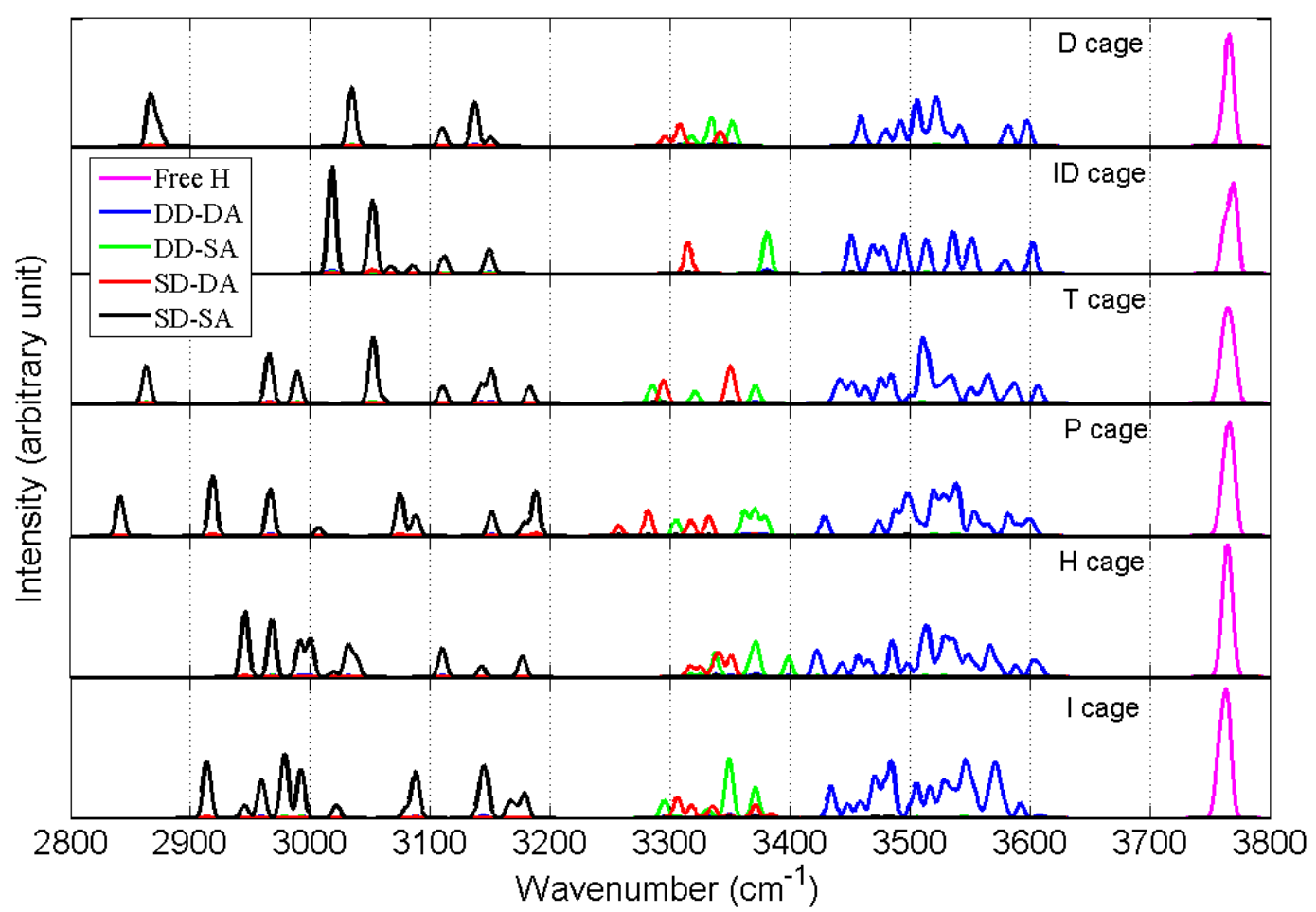

Figure 5. Raman spectra of $\mathrm{O}-\mathrm{H}$ stretching vibrational modes in various water cages from clathrate hydrates, divided into sub-spectra based on the contributions from different H-bond configurations.

\section{CONCLUSIONS}

In this work the anomalous $\mathrm{CH}$ stretching frequency shifts of hydrocarbon molecules in clathrate hydrates are elucidated. The present quantum-chemical calculations show that the $\mathrm{CH}$ stretching vibrational frequencies of hydrocarbon molecules in NGHs follow the trend predicted by the "loose cage - tight cage" model: when the size of the water cavity change from small to large, the $\mathrm{CH}$ stretching vibrational frequency of a trapped hydrocarbon molecule will first decrease and then increase until equal to that in gas phase; in the "tight cage" situation, the $\mathrm{CH}$ stretching vibrational frequency will be greater than in gas phase; in the "loose cage" situation, the $\mathrm{CH}$ stretching vibrational frequency will be below that in the gas phase. In addition, the 
dependence of the $\mathrm{OH}$ stretching frequencies on the H-bond configurations and the way the varying strengths of H-bonds for different configurations are reflected by the corresponding subspectra are demonstrated.

\section{ACKNOWLEDGEMENTS}

This work is supported by the Swedish Research Council (VR), the Swedish supercomputer center (SNIC/NSC), and a scholarship under the State Scholarship Fund of China Scholarship Council (File No. 201206060016).

\section{Supporting Information}

Computed and experimental $\mathrm{C}-\mathrm{H}$ stretching vibrational frequencies and the average $\mathrm{C}-\mathrm{H}$ bond length of hydrocarbon molecules in the gas phase and in water cages from clathrate hydrates, the C-H stretching frequencies of a guest molecule located at different positions in the water cage, and the configurations of different donor-acceptor combinations are supplemented in

the supporting information. This material is available free of charge via the internet at http://pubs.acs.org. 


\section{REFERENCES}

1. Sloan, E. D.; Koh, C. A., Clathrate Hydrates of Natural Gases. Third ed.; CRC Press/Taylor\&Francis Group: Boca Raton: 2008.

2. $\quad$ Gutt, C.; Asmussen, B.; Press, W.; Johnson, M. R.; Handa, Y. P.; Tse, J. S., The Structure of Deuterated Methane-Hydrate. J. Chem. Phys. 2000, 113, 4713-4721.

3. Rawn, C. J.; Rondinone, A. J.; Chakoumakos, B. C.; Circone, S.; Stern, L. A.; Kirby, S. H.; Ishii, Y., Neutron Powder Diffraction Studies as a Function of Temperature of Structure II Hydrate Formed from Propane. Can. J. Phys. 2003, 81, 431-438.

4. Udachin, K. A.; Ratcliffe, C. I.; Enright, G. D.; Ripmeester, J. A., Structure H Hydrate: A Single Crystal Diffraction Study of 2,2-Dimethylpentane $5\left(\mathrm{Xe}_{2} \mathrm{H}_{2} \mathrm{~S}\right) \cdot 34 \mathrm{H}_{2} \mathrm{O}$. Supramolecular Chemistry 1997, 8, 173-176.

5. Vatamanu, J.; Kusalik, P. G., Unusual Crystalline and Polycrystalline Structures in Methane Hydrates. J. Am. Chem. Soc. 2006, 128, 15588-15589.

6. $\quad$ Loveday, J. S.; Nelmes, R. J.; Guthrie, M.; Belmonte, S. A.; Allan, D. R.; Klug, D. D.; Tse, J. S.; Handa, Y. P., Stable Methane Hydrate above $2 \mathrm{GPa}$ and the Source of Titan's Atmospheric Methane. Nature 2001, 410, 661-663. 7. Loveday, J. S.; Nelmes, R. J.; Guthrie, M.; Klug, D. D.; Tse, J. S., Transition from Cage Clathrate to Filled Ice: The Structure of Methane Hydrate III. Physical Review Letters 2001, 87, 215501.

8. Vos, W. L.; Finger, L. W.; Hemley, R. J.; Mao, H. K., Novel $\mathrm{H}_{2}-\mathrm{H}_{2} \mathrm{O}$ Clathrates at High-Pressures. Phys. Rev. Lett. 1993, 71, 3150-3153.

9. $\quad$ Sloan, E. D., Fundamental Principles and Applications of Natural Gas Hydrates. Nature 2003, 426, 353-359.

10. Sum, A. K.; Koh, C. A.; Sloan, E. D., Clathrate Hydrates: From Laboratory Science to Engineering Practice. Ind. Eng. Chem. Res. 2009, 48, 7457-7465.

11. Koh, C. A., Towards a Fundamental Understanding of Natural Gas Hydrates. Chem. Soc. Rev. 2002, 31, 157-167.

12. Koh, C. A.; Sum, A. K.; Sloan, E. D., Gas Hydrates: Unlocking the Energy from Icy Cages. J. Appl. Phys. 2009, 106, 061101.

13. Subramanian, S.; Sloan, E. D., Trends in Vibrational Frequencies of Guests Trapped in Clathrate Hydrate Cages. J. Phys. Chem. B 2002, 106, 4348-4355.

14. Subramanian, S.; Kini, R. A.; Dec, S. F.; Sloan, E. D., Evidence of Structure II Hydrate Formation from Methane Plus Ethane Mixtures. Chemical Engineering Science 2000, 55, 1981-1999.

15. Sum, A. K.; Burruss, R. C.; Sloan, E. D., Measurement of Clathrate Hydrates Via Raman Spectroscopy. $J$. Phys. Chem. B 1997, 101, 7371-7377.

16. Subramanian, S.; Sloan, E. D., Microscopic Measurements and Modeling of Hydrate Formation Kinetics. Annals of the New York Academy of Sciences 2000, 912, 583-592.

17. Murshed, M. M.; Kuhs, W. F., Kinetic Studies of Methane-Ethane Mixed Gas Hydrates by Neutron Diffraction and Raman Spectroscopy. J. Phys. Chem. B 2009, 113, 5172-5180.

18. Uchida, T.; Takeya, S.; Kamata, Y.; Ikeda, I. Y.; Nagao, J.; Ebinuma, T.; Narita, H.; Zatsepina, O.; Buffett, B. A., Spectroscopic Observations and Thermodynamic Calculations on Clathrate Hydrates of Mixed Gas Containing Methane and Ethane: Determination of Structure, Composition and Cage Occupancy. J. Phys. Chem. B 2002, 106, 12426-12431.

19. Chazallon, B.; Focsa, C.; Charlou, J. L.; Bourry, C.; Donval, J. P., A Comparative Raman Spectroscopic Study of Natural Gas Hydrates Collected at Different Geological Sites. Chem. Geol. 2007, 244, 175-185.

20. Hester, K. C.; White, S. N.; Peltzer, E. T.; Brewer, P. G.; Sloan, E. D., Raman Spectroscopic Measurements of Synthetic Gas Hydrates in the Ocean. Marine Chem. 2006, 98, 304-314.

21. Hester, K. C.; Dunk, R. M.; White, S. N.; Brewer, P. G.; Peltzer, E. T.; Sloan, E. D., Gas Hydrate Measurements at Hydrate Ridge Using Raman Spectroscopy. Geochim. Cosmochim. Ac. 2007, 71, 2947-2959.

22. English, N. J.; MacElroy, J. M. D., Perspectives on Molecular Simulation of Clathrate Hydrates: Progress, Prospects and Challenges. Chemical Engineering Science 2015, 121, 133-156.

23. Jacobson, L. C.; Hujo, W.; Molinero, V., Amorphous Precursors in the Nucleation of Clathrate Hydrates. $J$. Am. Chem. Soc. 2010, 132, 11806-11811.

24. Jacobson, L. C.; Molinero, V., Can Amorphous Nuclei Grow Crystalline Clathrates? The Size and Crystallinity of Critical Clathrate Nuclei. J. Am. Chem. Soc. 2011, 133, 6458-6463.

25. Vatamanu, J.; Kusalik, P. G., Observation of Two-Step Nucleation in Methane Hydrates. Phys. Chem. Chem. Phys. 2010, 12, 15065-15072.

26. Guo, G. J.; Li, M.; Zhang, Y. G.; Wu, C. H., Why Can Water Cages Adsorb Aqueous Methane? A Potential 
of Mean Force Calculation on Hydrate Nucleation Mechanisms. Phys. Chem. Chem. Phys. 2009, 11, 10427-10437.

27. Guo, G. J.; Zhang, Y. G.; Liu, C. J.; Li, K. H., Using the Face-Saturated Incomplete Cage Analysis to Quantify the Cage Compositions and Cage Linking Structures of Amorphous Phase Hydrates. Phys. Chem. Chem. Phys. 2011, 13, 12048-12057.

28. English, N. J.; MacElroy, J. M. D., Theoretical Studies of the Kinetics of Methane Hydrate Crystallization in External Electromagnetic Fields. J. Chem. Phys. 2004, 120, 10247-10256.

29. English, N. J.; Lauricella, M.; Meloni, S., Massively Parallel Molecular Dynamics Simulation of Formation of Clathrate-Hydrate Precursors at Planar Water-Methane Interfaces: Insights into Heterogeneous Nucleation. J. Chem. Phys. 2014, 140, 204714.

30. Lauricella, M.; Meloni, S.; English, N. J.; Peters, B.; Ciccotti, G., Methane Clathrate Hydrate Nucleation Mechanism by Advanced Molecular Simulations. J. Phys. Chem. C 2014, 118, 22847-22857.

31. Liu, Y.; Ojamäe, L., C-C Stretching Raman Spectra and Stabilities of Hydrocarbon Molecules in Natural Gas Hydrates: A Quantum Chemical Study. J. Phys. Chem. A 2014, 118, 11641.

32. Liu, Y.; Zhao, J. J.; Li, F. Y.; Chen, Z. F., Appropriate Description of Intermolecular Interactions in the Methane Hydrates: An Assessment of DFT Methods. J. Comput. Chem. 2013, 34, 121-131.

33. Liu, Y.; Zhao, J. J.; Xu, J. C., Dissociation Mechanism of Carbon Dioxide Hydrate by Molecular Dynamic Simulation and Ab Initio Calculation. Comput. Theor. Chem. 2012, 991, 165-173.

34. Cao, X. X.; Su, Y.; Liu, Y.; Zhao, J. J.; Liu, C. L., Storage Capacity and Vibration Frequencies of Guest Molecules in $\mathrm{CH}_{4}$ and $\mathrm{CO}_{2}$ Hydrates by First-Principles Calculations. J. Phys. Chem. A 2014, 118, $215-222$.

35. Tang, L. L.; Su, Y.; Liu, Y.; Zhao, J. J.; Qiu, R. F., Nonstandard Cages in the Formation Process of Methane Clathrate: Stability, Structure, and Spectroscopic Implications from First-Principles. J. Chem. Phys. 2012, 136, 224508.

36. Huang, Y.; Liu, Y.; Su, Y.; Zhao, J., Dissociation Mechanism of Gas Hydrates (I, II, H) of Alkane Molecules: A Comparative Molecular Dynamics Simulation. Mol. Simulat. 2014, DOI: 10.1080/08927022.2014.940522.

37. Lenz, A.; Ojamäe, L., Structures of the I-, II- and H-Methane Clathrates and the Ice-Methane Clathrate Phase Transition from Quantum-Chemical Modeling with Force-Field Thermal Corrections. J. Phys. Chem. A 2011, $115,6169-6176$.

38. Li, Q.; Kolb, B.; Roman-Perez, G.; Soler, J. M.; Yndurain, F.; Kong, L. Z.; Langreth, D. C.; Thonhauser, T., $\mathrm{Ab}$ Initio Energetics and Kinetics Study of $\mathrm{H}_{2}$ and $\mathrm{CH}_{4}$ in the SI Clathrate Hydrate. Phys. Rev. B 2011, 84, 153103.

39. Roman-Perez, G.; Moaied, M.; Soler, J. M.; Yndurain, F., Stability, Adsorption, and Diffusion of $\mathrm{CH}_{4}, \mathrm{CO}_{2}$, and $\mathrm{H}_{2}$ in Clathrate Hydrates. Phys. Rev. Lett. 2010, 105, 145901.

40. Patchkovskii, S.; Tse, J. S., Thermodynamic Stability of Hydrogen Clathrates. Proc. Natl. Acad. Sci. USA/PNAS 2003, 100, 14645-14650.

41. Kumar, P.; Sathyamurthy, N., Theoretical Studies of Host-Guest Interaction in Gas Hydrates. J. Phys. Chem. A 2011, 115, 14276-14281.

42. Ramya, K. R.; Kumar, G. V. P.; Venkatnathan, A., Raman Spectra of Vibrational and Librational Modes in Methane Clathrate Hydrates Using Density Functional Theory. J. Chem. Phys. 2012, 136, 174305.

43. Ramya, K. R.; Venkatnathan, A., Stability and Reactivity of Methane Clathrate Hydrates: Insights from Density Functional Theory. J. Phys. Chem. A 2012, 116, 7742-7745.

44. Ikeda, T.; Terakura, K., Structural Transformation of Methane Hydrate from Cage Clathrate to Filled Ice. J. Chem. Phys. 2003, 119, 6784-6788.

45. Hiratsuka, M.; Ohmura, R.; Sum, A. K.; Yasuoka, K., Molecular Vibrations of Methane Molecules in the Structure I Clathrate Hydrate from Ab Initio Molecular Dynamics Simulation. J. Chem. Phys. 2012, $136,044508$.

46. Hiratsuka, M.; Ohmura, R.; Sum, A. K.; Yasuoka, K., Vibrational Modes of Methane in the Structure H Clathrate Hydrate from Ab Initio Molecular Dynamics Simulation. J. Chem. Phys. 2012, 137, 144306.

47. Tse, J. S., Vibrations of Methane in Structure I Clathrate Hydrate - an Ab Initio Density Functional Molecular Dynamics Study. J. Supramol. Chem. 2002, 2, 429.

48. Jiang, H.; Jordan, K. D.; Taylor, C. E., Molecular Dynamics Simulations of Methane Hydrate Using Polarizable Force Fields. J. Phys. Chem. B 2007, 111, 6486-6492.

49. Pimentel, G. C.; Charles, S. W., Infrared Spectral Perturbations in Matrix Experiments. Pure Appl. Chem. 1963, 7, 111-123.

50. McDonald, S.; Ojamäe, L.; Singer, S. J., Graph Theoretical Generation and Analysis of Hydrogen-Bonded Structures with Applications to the Neutral and Protonated Water Cube and Dodecahedral Clusters. J. Phys. Chem. A 1998, 102, 2824-2832.

51. Lawson, C. L.; Zhang, R. G.; Schevitz, R. W.; Otwinowski, Z.; Joachimiak, A.; Sigler, P. B., Flexibility of the DNA-Binding Domains of Trp Repressor. Protein-Struct. Funct. Genet. 1988, 3, 18-31. 
52. Chai, J. D.; Head-Gordon, M., Long-Range Corrected Hybrid Density Functionals with Damped AtomAtom Dispersion Corrections. Phys. Chem. Chem. Phys. 2008, 10, 6615-6620.

53. Frisch, M. J.; Trucks, G. W.; Schlegel, H. B.; Scuseria, G. E.; Robb, M. A.; Cheeseman, J. R.; Scalmani, G.; Barone, V.; Mennucci, B.; Petersson, G. A.. et al. Gaussion 09, Revision C.01; Gaussion Inc.: Wallingford CT, 2011.

54. Liu, Y.; Ojamäe, L., Fingerprints in IR OH Vibrational Spectra of $\mathrm{H}_{2} \mathrm{O}$ Clusters from Different $\mathrm{H}-\mathrm{Bond}$ Conformations by Means of Quantum-Chemical Computations. J. Mol. Model. 2014, 20, 2281.

55. Lenz, A.; Ojamäe, L., Theoretical IR Spectra for Water Clusters $\left(\mathrm{H}_{2} \mathrm{O}\right)_{\mathrm{N}}(\mathrm{N}=6-22,28,30)$ and Identification of Spectral Contributions from Different H-Bond Conformations in Gaseous and Liquid Water. J. Phys. Chem. A 2006, 110, 13388-13393.

56. Koch, W.; Holthausen, M. C., A Chemist's Guide to Density Functional Theory. Second Edition ed.; WILEY-VCH: Weinheim, 2000.

57. Buckingham, A. D., Solvent Effects in Infra-Red Spectroscopy. Proc. R. Soc. Lond. A 1958, $248,169-182$.

58. Ojamäe, L.; Hermansson, K.; Probst, M., The OH Stretching Frequency in Liquid Water Simulations - the Classical Error. Chem. Phys. Lett. 1992, 191, 500-506.

59. Kuo, J. L.; Ciobanu, C. V.; Ojamäe, L.; Shavitt, I.; Singer, S. J., Short H-Bonds and Spontaneous SelfDissociation in $\left(\mathrm{H}_{2} \mathrm{O}\right)_{20}$ : Effects of H-Bond Topology. J. Chem. Phys. 2003, 118, 3583-3588.

60. Badger, R. M.; Bauer, S. H., Spectroscopic Studies of the Hydrogen Bond. II. The Shift of the O-H Vibrational Frequency in the Formation of the Hydrogen Bond. J. Chem. Phys. 1937, 5, 839-851.

61. Huggins, C. M.; Pimentel, G. C., Systematics of the Infrared Spectral Properties of Hydrogen Bonding Systems: Frequency Shift, Half Width and Intensity. J. Phys. Chem. 1956, 60, 1615-1619.

62. Mecke, R., Infra-Red Spectra of Hydroxylic Compounds. Discuss. Faraday Soc. 1950, 9, 161-177. 
Table of Contents Image

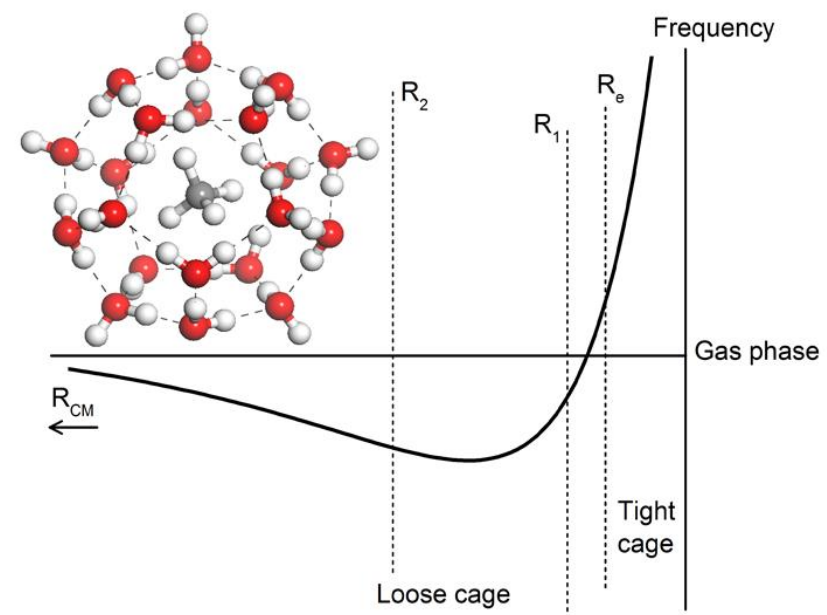

